\title{
Consideration of Maxillary Skeletal Expansion (MSE) and Mandibular Symphyseal Distraction Osteogenesis (MSDO) for the Treatment of Sleep Apnea and Snoring
}

\author{
Sylvain Chamberland, D.M.D., M.Sc, F.R.C.D. (C)
}

Private Practice

\begin{abstract}
Patients who are predisposed to obstructive sleep apnea (OSA) often have upper airway obstruction in the nasopharynx or the oropharynx. Mandibular advancement and tongue-restraining devices are usually effective options for the management of OSA in selected patients. However, positive airway pressure therapy is considered the gold standard treatment for the management of OSA in adults. Maxillomandibular advancement surgery is an effective surgical technique for treatment of moderate to severe OSA. The role of the transverse maxillomandibular dimension (TMMD) in OSA is not fully understood, but recent reports appear to confirm that normalizing TMMD may assist in the treatment of OSA. With the help of two case reports, this manuscript reviews the mechanics used to change TMMD. These cases illustrate that patients may benefit from just increasing the TMMD alone, or both TMMD and anteroposterior measurements, if they experience snoring and OSA. TMMD followed by bimaxillary advancement, when indicated, might be more effective than maxillomandibular advancement alone.
\end{abstract}

Keywords: maxillary distraction, mandibular distraction, snoring, OSA

Citation: Chamberland S. Consideration of Maxillary Skeletal Expansion (MSE) and Mandibular Symphyseal Distraction Osteogenesis (MSDO) for the Treatment of Sleep Apnea and Snoring. J Dent Sleep Med. 2020;7(2)

\section{CONSIDERATION OF MAXILLARY SKELETAL EXPANSION AND MANDIBULAR SYMPHYSEAL DISTRACTION OSTEOGENESIS FOR THE TREATMENT OF SLEEP APNEA AND SNORING}

Obstructive sleep apnea (OSA) is a chronic illness that affects both adults and children. Estimates of the prevalence of OSA in adults is reportedly $14 \%$ in men and $5 \%$ in women, and $1 \%$ to $6 \%$ of children. ${ }^{1,2}$ Risk factors commonly associated with OSA include obesity, menopause, male gender, and advancing age. The obstruction in the upper airway is rarely at a single anatomic site. The two major sites of obstruction are in the nasopharynx (retropalatal) and the oropharynx (retroglossal). ${ }^{3}$ Patients who are predisposed to OSA may also have craniofacial characteristics such as retrognathia, long narrow face, and a tapered deep palate. However, the relationship between any dentofacial deformity and the development of OSA has not been well established. Undiagnosed OSA may coexist with various comorbidities such as obesity, diabetes, cardiovascular events, stroke, and death. Therefore, OSA is a serious public health problem. ${ }^{2,4}$

\section{Treatment Method}

Mandibular advancement and tongue-restraining devices are usually effective options for the management of OSA in selected patients. However, positive airway pressure therapy is considered the gold standard for managing OSA in adults. ${ }^{1,5}$ However, oral appliances cause the teeth to move, which can result in undesirable adverse effects. Long- term use of oral appliances may result in decreasing the overjet, retroclination of the maxillary incisors and proclination of the mandibular incisors. Although these dentoalveolar changes may be unnoticed by most patients, some of these changes may adversely alter dental and occlusal relationships. Patients should be advised about these potential changes to their dentition and regular occlusal reassessments are recommended during treatment in patients with OSA-hypopnea syndrome. ${ }^{6}$

Sleep apnea patients with demonstrable retrognathic jaw relationships should be informed that bimaxillary advancement surgery is effective in decreasing excessive daytime sleepiness, snoring, and apneas, even with severe OSA (apnea-hypopnea index $[\mathrm{AHI}]>100){ }^{3,4,7}$

Conley and Legan ${ }^{8}$ reported on a patient who had undergone bimaxillary transverse distraction osteogenesis and maxillomandibular advancement (MMA) for the correction of severe OSA. This case illustrated the functional benefit of increasing both transverse maxillomandibular dimension and anteroposterior dimension in selected patients. 


\section{HISTORY AND DIAGNOSIS}

\section{Patient 1}

A 38-year-old patient consulted an otolaryngologist for severe snoring. His body mass index was $22,7 \mathrm{~kg} / \mathrm{m}^{2}$. Polysomnography did not reveal sleep apnea syndrome $(\mathrm{AHI}=3)$. The patient was then referred to an oral and maxillofacial surgeon who referred to the author for the correction of the malocclusion.

Clinical examination revealed a class I mutilated occlusion with missing lower right central and lateral incisors. Both maxillary and mandibular arch were Vshaped and constricted. Gingival recession was noted buccal to the lower canines and lower left central incisor indicating that baseline bone loss was present. (Figure 1). The incisor showing appeared normal in repose and the patient's smile line showed more gingiva on the right posterior and a super erupted right maxillary canine causing a cant of the occlusal plane to the right (Figure 2). Maxillary third molars were present and super erupted (Figure 3).

Figure 1. Pretreatment intraoral photographs showing gingival recession.
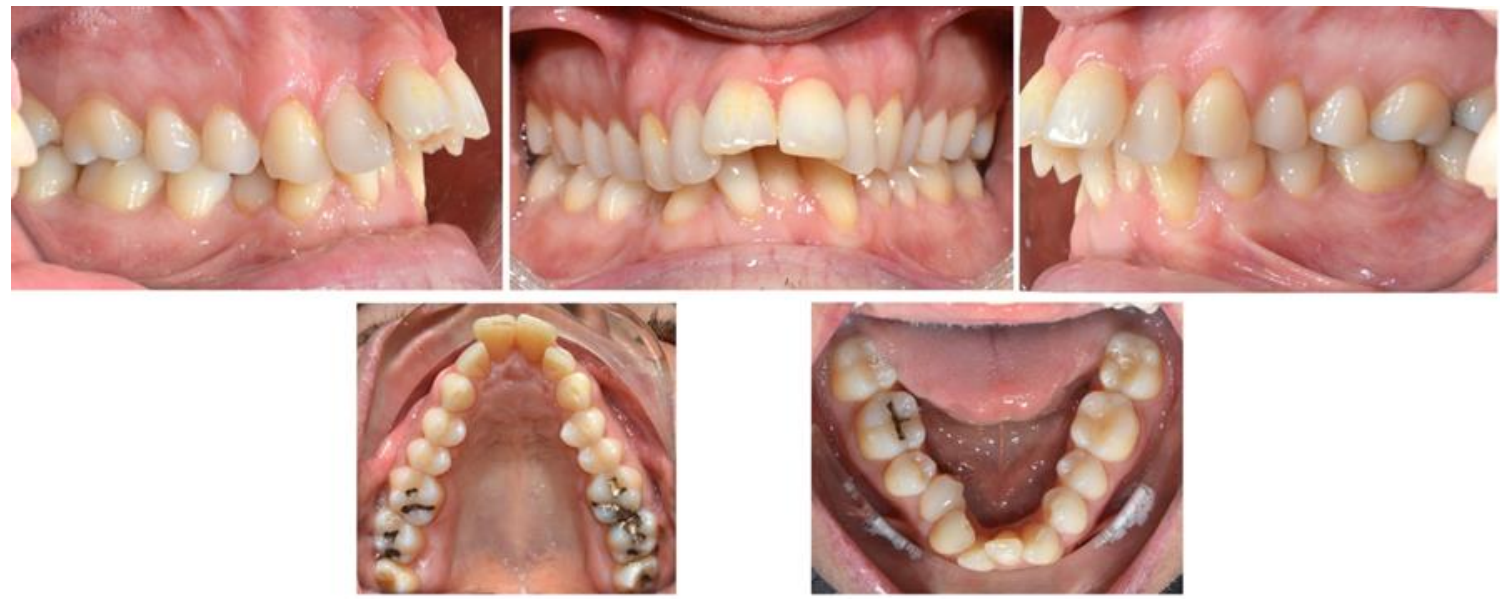

Figure 2. Pretreatment extraoral photographs showing a normal-appearing incisor in repose a smile line with more gingiva on the right posterior side, and a super erupted right maxillary canine causing a cant of the occlusal plane to the right.
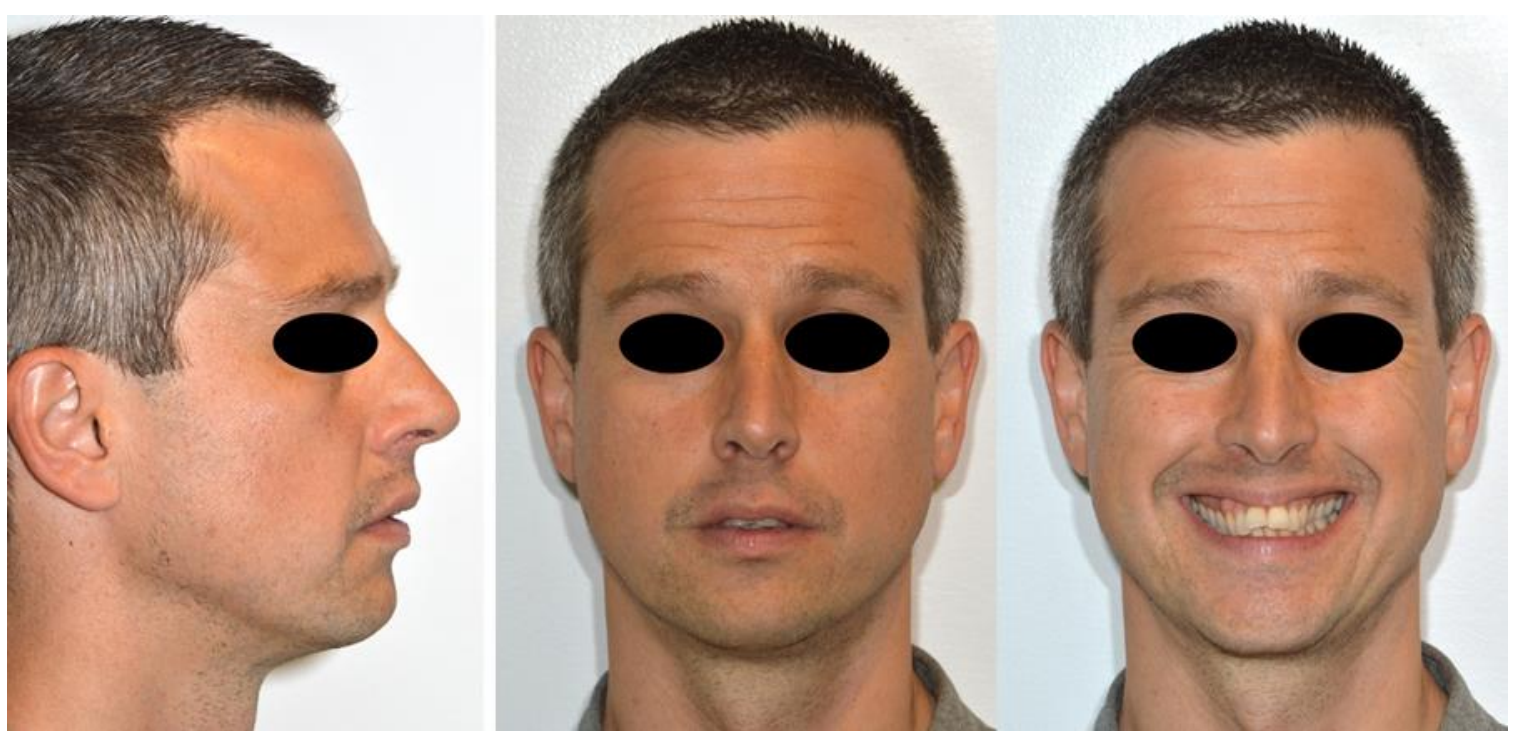
Figure 3. Pretreatment orthopantomogram showing supererupted maxillary third molars.

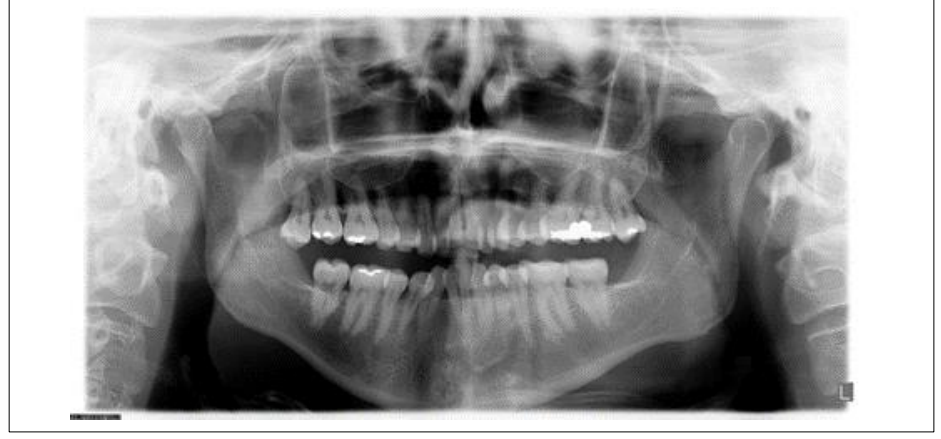

The cephalometric analysis revealed that both jaws had a retrusive relationship relative to the cranial base. The mandibular plane angle was hyperdivergent. The maxillary incisors were proclined, whereas the mandibular incisors were retroclined. The airway shadow of the oropharynx is $4 \mathrm{~mm}$ at the level of the gonial angle (Figure 4).

Figure 4. Pretreatment lateral cephalogram showing the airway shadow of the oropharynx.

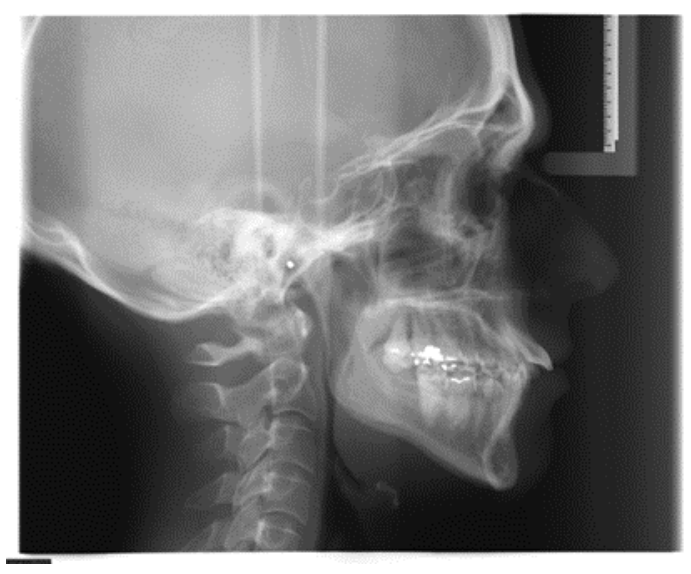

\section{Treatment Objective}

The primary treatment objective was to resolve protruded maxillary incisors and large overjet. The plan was to address the maxillary and mandibular deficiencies and the retrognathic mandible in a two-stage surgical orthodontic approach. The secondary objective was to resolve snoring.

The first stage included a surgically assisted rapid palatal expansion (SARPE) ${ }^{9}$ and mandibular symphyseal distraction osteogenesis to open space to restore the missing incisors. After reassessment of the first-stage outcome, the second stage was for the patient to undergo MMA if necessary.

SARPE would provide the space necessary to retrocline the maxillary incisors to achieve an ideal anteroposterior angulation. Symphyseal distraction would help to coordinate the width of both arches and gain space to restore the missing incisors. Recent reports of hybrid mandibular distractors show greater skeletal and more parallel expansion than a tooth-borne distractor ${ }^{10}$ with stable long-term results. ${ }^{11,12}$

An alternate treatment plan would be to extract two maxillary premolars and retract the maxillary incisors, and level and align the lower arch, followed by MMA surgery. This approach would have maintained the constricted mandibular arch and the dental asymmetry created by unilateral loss of two incisors that would have to be camouflaged with surgical advancement. This would commit the patient to a second surgery.

\section{Treatment Progress}

The SARPE procedure involved the separation of the pterygoid junction and midpalatal suture. A separation of 1 to $1.5 \mathrm{~mm}$ was achieved perioperatively. ${ }^{13}$

The mandibular distraction device used was the Bologna distractor (KLS Martin, Jacksonville, Florida, USA). It has bilateral wings than can be fixed on the symphysis with up to five screws per side and connectors that can be adapted and bonded to the occlusal surface of the premolars.

The mandible is osteotomized vertically in the symphysis area after proper adaptation of the distractor elements. The distractor can also be adapted on a threedimensional model before surgery. In this case, an oblique osseous cut toward missing incisors site was made to avoid the tooth roots. The distraction device was activated $1 \mathrm{~mm}$ peroperatively (Figure 3 and 5).

Figure 5. The Bologna distractor is shown in situ prior to soft-tissue closure. The distraction device was activated 1 $\mathrm{mm}$ per day.

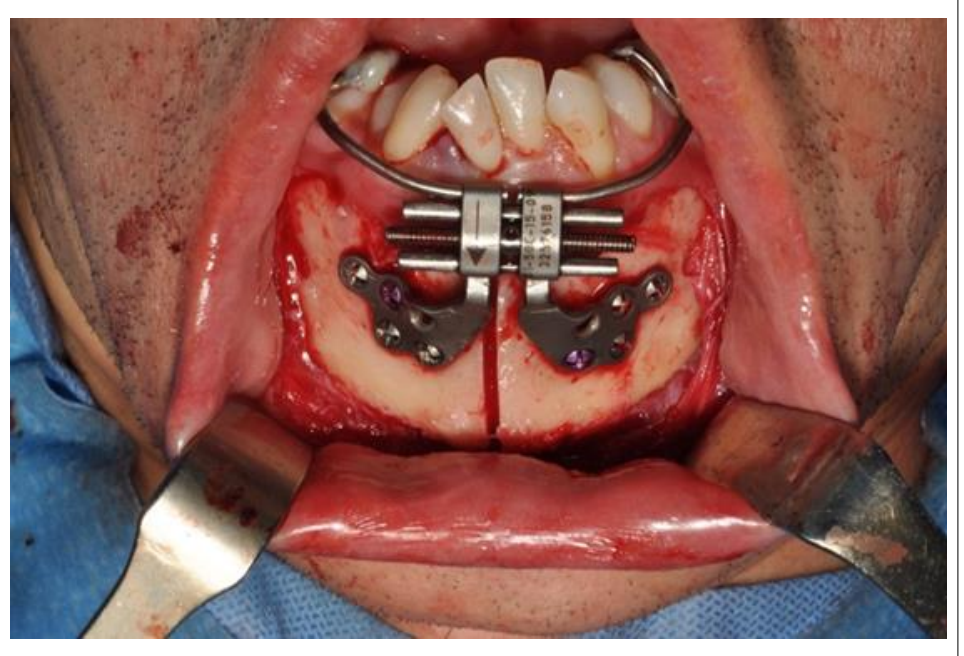

Seven days after surgery, the patient was instructed to activate both appliances. The rate of activation was $0,5 \mathrm{~mm}$ per day in the maxilla and $1 \mathrm{~mm}$ per day in the mandible. The maxillary distraction stopped at 17 days postoperatively. Eight $\mathrm{mm}$ of first molar expansion was achieved. The mandibular distraction stopped at 24 days 
Figure 6. Photographs showing the patient's teeth during treatment. A, End of distraction shows a maxillary diastema of $9.5 \mathrm{~mm}$ and the mandibular intercanine width change of $10 \mathrm{~mm}$. B, At 1 month, the patient noted the screw became narrower. A loss of $4 \mathrm{~mm}$ was measured. C, After 4 weeks, $3.5 \mathrm{~mm}$ was regained.

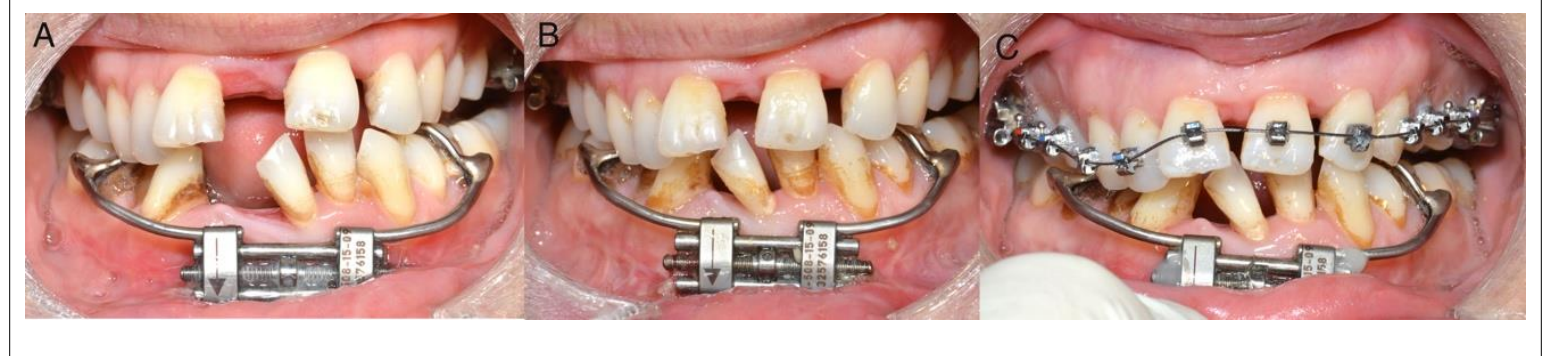

Figure 7. Cephalogram obtained after 3 months of treatment, and 1 month after maxillary distraction. Arrows indicate the palatal distraction site, the maxillary osteotomy site at Jugula (Jg), and the osteotomy site at the mandibular symphysis. Note the parallelism of the left and right mandibular distraction sites.

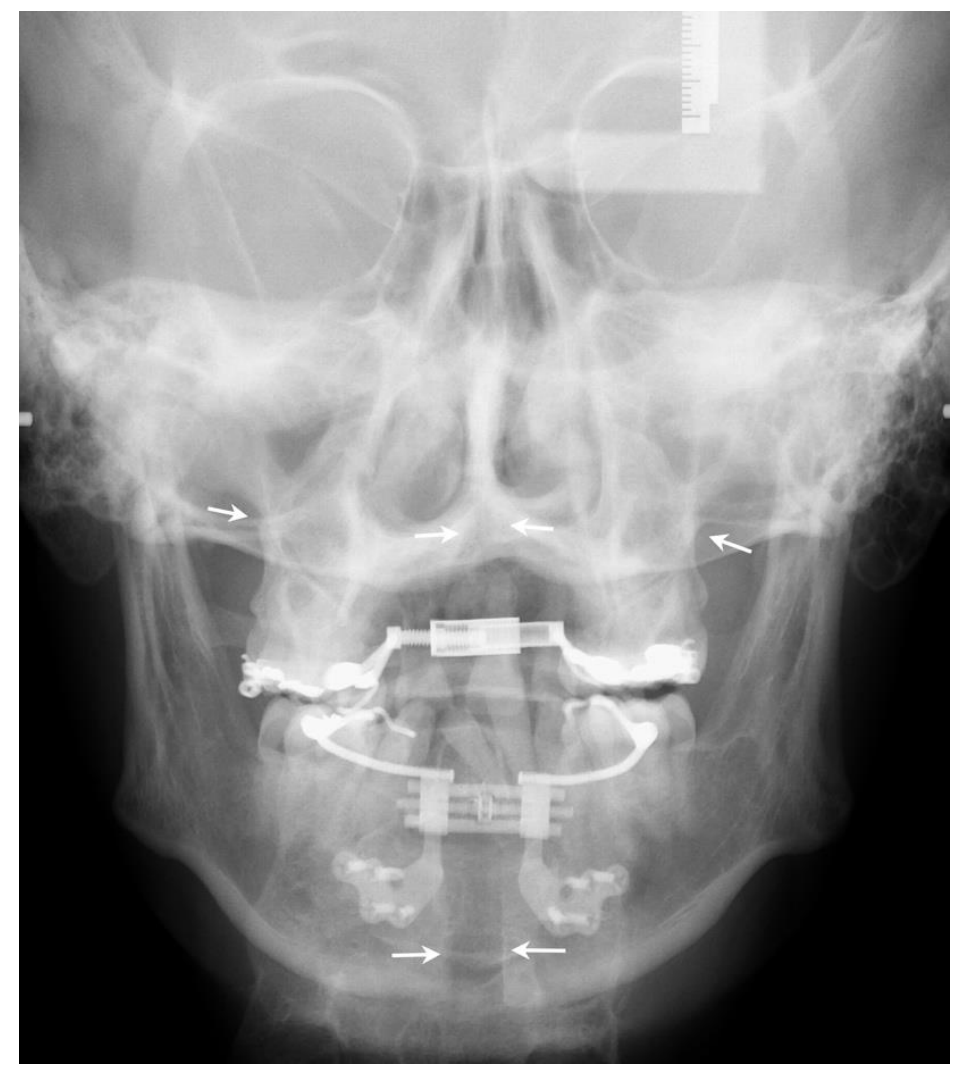

after $10 \mathrm{~mm}$ of distraction had been achieved.

It was determined that the screw deactivated itself during the day. This explained why it took 24 days to achieve $10 \mathrm{~mm}$ of distraction. The patient noted at 4 weeks postdistraction that the device appeared to have closed. We reactivated the device for another month and were able to achieve the preplanned $10 \mathrm{~mm}$ of distraction (Figure 6).

The maxillary teeth were bonded, and a continuous arch-wire was placed. The mandibular device was locked into position using a steel ligature and composite bonding.

The posteroanterior cephalogram obtained at the end of distraction shows parallel expansion and $9 \mathrm{~mm}$ of separation of the mandibular halves and reossification of the midpalatal distraction site (Figure 7).

At 5 weeks postdistraction, the mandibular teeth were bonded to initiate alignment. 
The maxillary distractor was removed at 31 weeks and the mandibular distractor was removed at 36 weeks. The orthopantomogram demonstrates a radiolucency that was explained by the fact that we had to re-start the distraction 1 month after having stopped it to achieve our goal. A bone graft was then required to permit the placement of a dental implant (Figure 8).

Figure 8. Radiorgaphic view. A. At the removal of the distraction device, radiolucencies were noted. B- Follow-up 2 months after autogenous grafting.
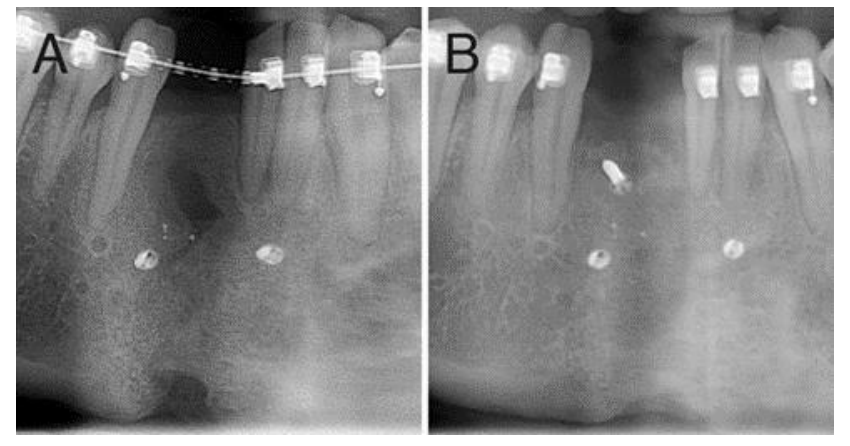

Reassessment of the dental and transverse changes at 69 weeks confirmed the presence of a class I skeletal relationship, straight facial profile, and lip competence in repose. The patient also reported that he had stopped snoring. Because there was no evidence at baseline of sleep apnea, and a class I occlusion had been achieved, we concluded that the second surgical phase was not necessary as well as a second polysomnography.

The mandibular dental implant was placed at 82 weeks and the patient was debanded at 94 weeks. Intraoral photographs taken upon implant placement show a dehiscence buccal to the canine and lateral incisor. Followup radiographs showed healing and adjustment of the bone to the level of the cervix of the implant. No further bone loss can be noted proximal to the root of canine and the lateral incisors (Figure 9).

\section{Treatment Results}

A class I occlusion was achieved with ideal overjet and overbite with ideal width to restore the two missing incisors (Figure 10).

Follow-up at 19 weeks into retention shows the dental restoration in place (Figure 11, A). Progression of the gingival recession is noted on the lower right canine and lower left central incisor. The patient was referred to a periodontist for an autogenous gingival graft (Figure 11, B). The gingival recession can be explained by the thin gingival phenotype and the presence of recession and bone loss at baseline. This is confirmed at implant placement (Figure 9A).

Figure 9. A and B, Intraoral photographs showing the bone level near the implant site. C, Followup radiograph at 13 days. $D$, Follow-up radiograph at 72 weeks.
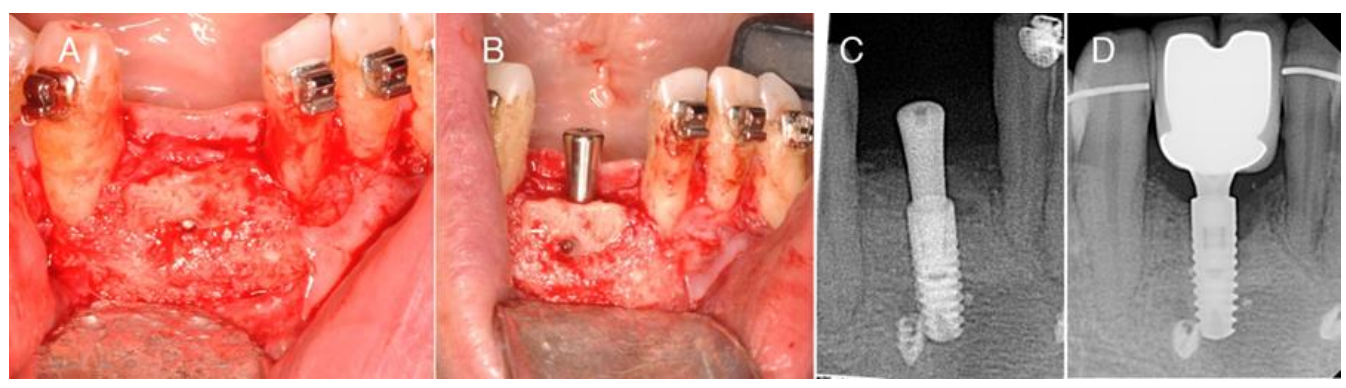

Figure 10. Posttreatment intraoral photographs. A, B and C show class I occlusion with ideal overjet and overbite. $E$, the implant was centered in the edentulous space to permit the placement of the two incisors. D and E, significant widening of the dental arches was obtained.
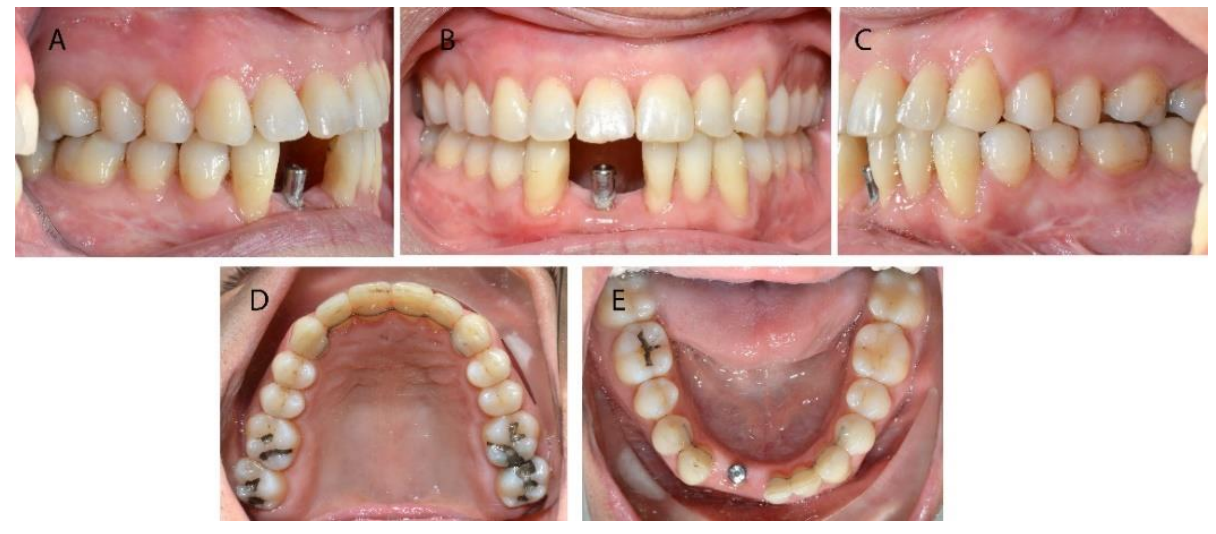
Figure 11. Intraoral photographs. A, Follow-up at 19 weeks into retention. Gingival recession is noted. B, Follow-up at 131 weeks into retention showing stable occlusion and gingival grafting.
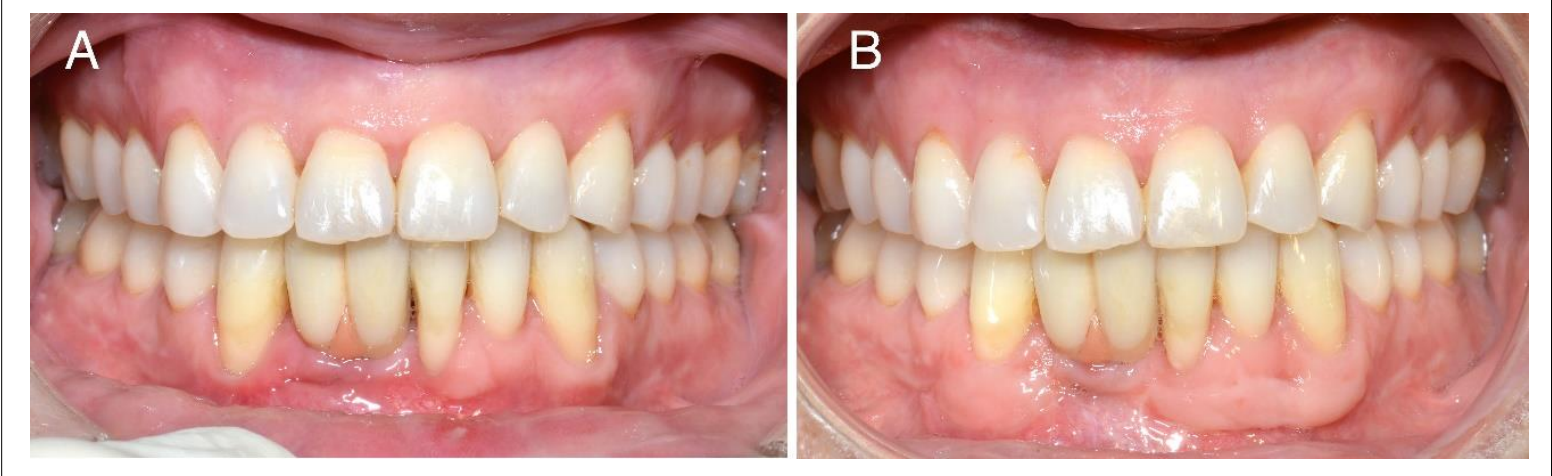

\begin{tabular}{|c|c|c|c|c|c|c|}
\hline \multicolumn{7}{|c|}{ Table 1. Dimensional transverse changes in Patient 1 and Patient 2} \\
\hline & \multicolumn{3}{|c|}{ Patient 1} & \multicolumn{3}{|c|}{ Patient 2} \\
\hline Dental & $\begin{array}{l}\text { Baseline } \\
(\mathrm{mm})\end{array}$ & $\begin{array}{l}\text { Final } \\
(\mathrm{mm})\end{array}$ & $\begin{array}{c}\Delta \\
(\mathrm{mm})\end{array}$ & $\begin{array}{l}\text { Baseline } \\
(\mathrm{mm})\end{array}$ & $\begin{array}{l}\text { Progress } \\
(\mathrm{mm})\end{array}$ & $\begin{array}{c}\Delta \\
(\mathrm{mm})\end{array}$ \\
\hline Mx 1st Molar & 40.17 & 48.22 & 8.05 & 34.2 & 43.9 & 9.7 \\
\hline Mx Canine & 25.2 & 33.54 & 8.34 & 26.6 & 33.3 & 6.7 \\
\hline Md 1st molar & 33.69 & 42 & 8.31 & 36 & 43 & 7 \\
\hline Md Canine & 12.42 & 24.32 & 11,9 & 21.5 & 27.5 & 6 \\
\hline $\begin{array}{l}\text { Skeletal } \\
\text { Mx width (Jg-Jg) }\end{array}$ & 59.6 & 64.4 & 4.8 & 58,8 & 63.6 & 4.8 \\
\hline MdWidth & 89.1 & 90.7 & 1.6 & 81.6 & 83.1 & 1.5 \\
\hline $\begin{array}{l}\text { Nasal Cavity } \\
\text { width }\end{array}$ & 34.7 & 36.4 & 1,7 & 27.6 & 32,3 & 4.7 \\
\hline Soft tissue & & & & & & \\
\hline Airway shadow & 4.9 & 10.1 & 5.2 & na & na & na \\
\hline
\end{tabular}

The change in the transverse dimension shows a maxillary expansion of $8 \mathrm{~mm}$ or so at the first molar and the canine. In the mandibular arch $8.4 \mathrm{~mm}$ was gained at the first molar, and $11.9 \mathrm{~mm}$ at the canine. Maxillary width increased by $4.8 \mathrm{~mm}$ at jugular and $1.6 \mathrm{~mm}$ at the antegonial notch. The airway shadow at gonial angle increased by $5.2 \mathrm{~mm}$ (Table 1).

Comparison of initial and final cephalogram confirm retraction and uprighting of maxillary incisors, proclination of mandibular incisors, and increased airway shadow (Figures 4 and 12).

Extraoral photos reveal a straight facial profile. The smile display shows a cant of the occlusal plane that was not noticed by the patient. (Figure 13).

\section{Patient 2}

The second patient was a 29-year-old woman in whom severe OSA was diagnosed. Polysomnography revealed an AHI of 35 events/h. Her initial symptoms included severe snoring, excessive daytime sleepiness with an Epworth
Figure 12. Posttreatment cephalogram.

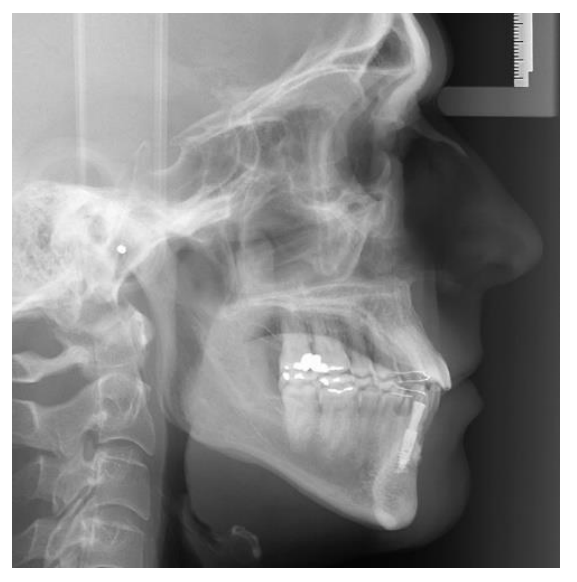

Sleepiness Scale score of 14/24, reported cessation of breathing during night, and nonrefreshing sleep. She was taking $10 \mathrm{mg}$ of escitalopram (Cipralex) at bedtime to help control her anxiety. She had an increased neck perimeter and a body mass index of $39 \mathrm{~kg} / \mathrm{m}^{2}$, indicating she was overweight. The patient had a hiatal hernia and 
Figure 13. Extraoral final photos show a straight facial profile.
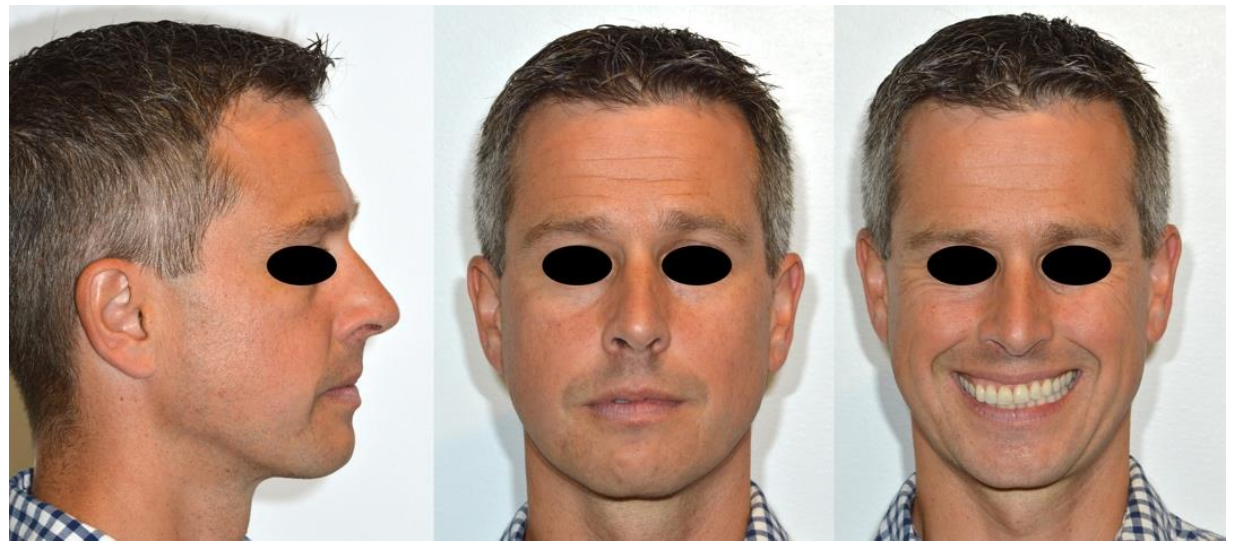

Figure 14. Intraoral photographs showing class I occlusion and moderate crowing (B), and constricted dental arches $(A, C)$.

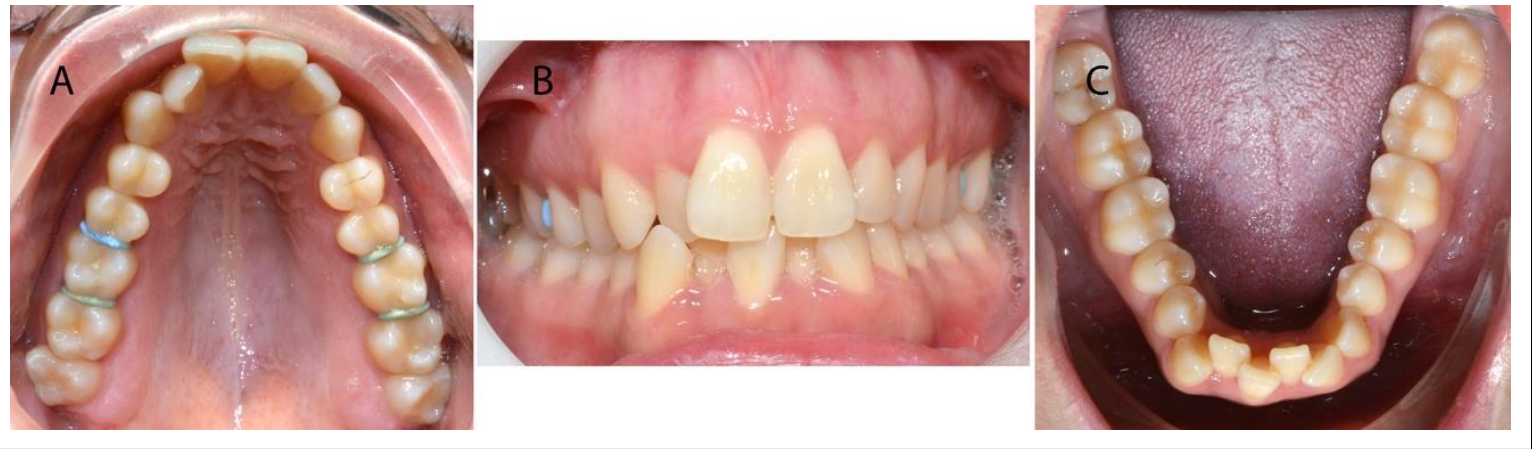

Figure 15. Initial cephalogram $(A)$ show retrusive maxilla $\left(S N A=75^{\circ}\right)$ and mandible $\left(S N B=72^{\circ}\right)$. Facial photographs show smile view shows narrow maxillary arch width wide buccal corridor $(\mathrm{C})$. The increased neck circumference is obvious on the frontal and profile photo $(B, C)$.
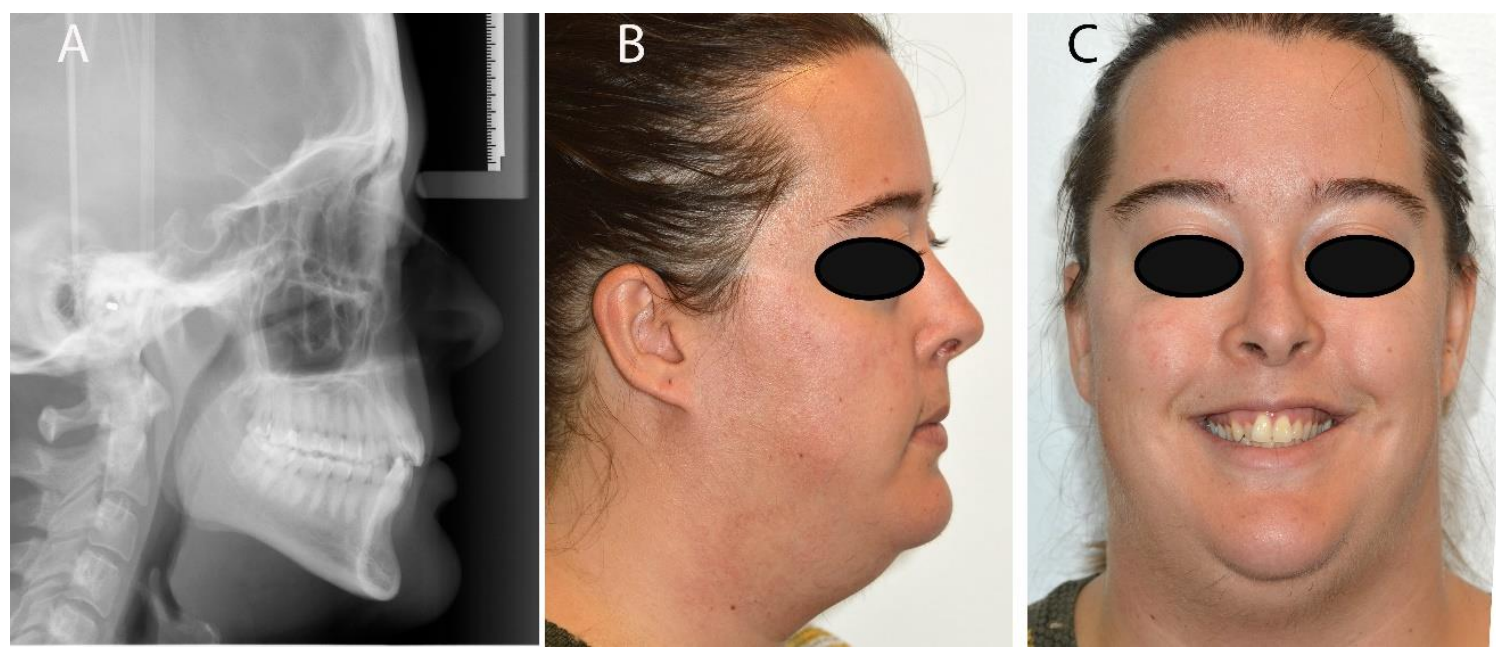

gastrointestinal reflux treated with Nexium (esomeprazole). Continuous positive airway pressure had been prescribed, but the report of its use revealed very low compliance because it was only used approximately 4.5 hours per night for 10 nights over a 90 -day period. The
ENT specialist performed a septoplasty and an inferior turbinoplasty before referring to the orthodontist.

Clinical examination revealed a class I occlusion, moderate crowding, and constricted maxillary and mandibular arches (Figure 14). The cephalometric analysis 
Figure 16. Intraoral photographs showing the end of the second maxillary skeletal expansion (A, $B$ ) and 5 months after the end of mandibular distraction $(B, C)$.

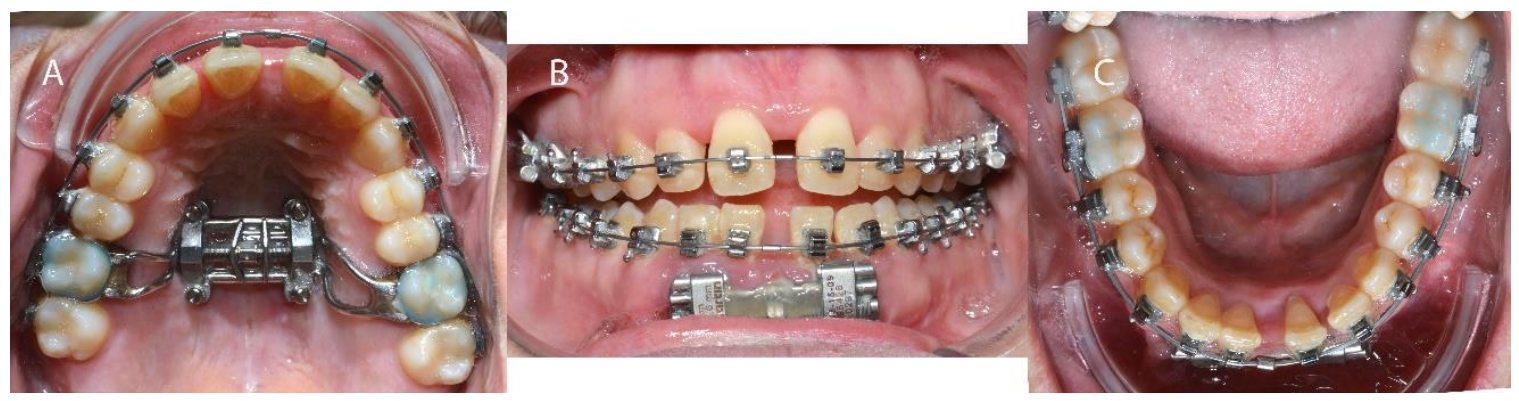

Figure 17. Initial and progress posteroanterior cephalograms. Progress PA cephalogram shows midpalatal separation and parallel mandibular distraction at the symphysis.
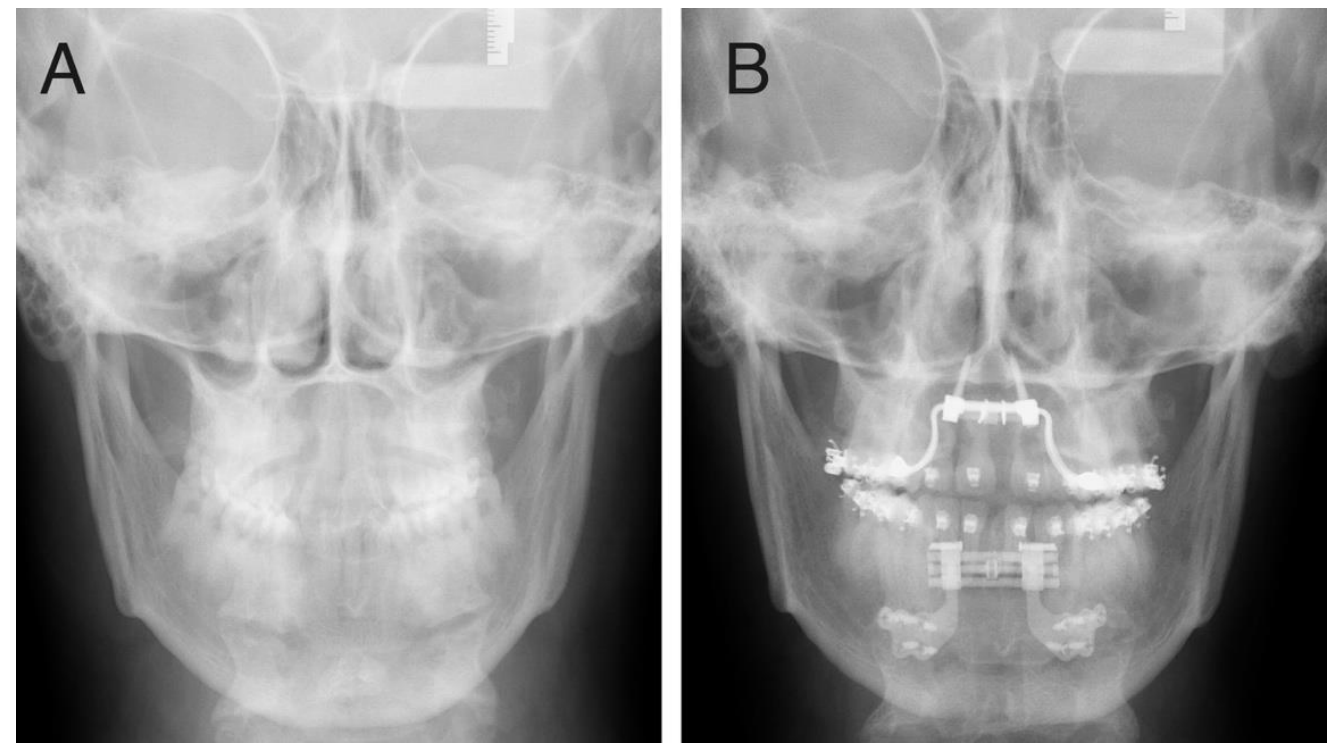

Figure 18. Intraoral photographs showing distraction device at baseline $(A)$ and distractor at removal $(B)$. Photography $(B)$ and radiography $(C)$ showing reossification of the mandibular distraction site, but a bone defect mesial to lower left central incisor is noted.
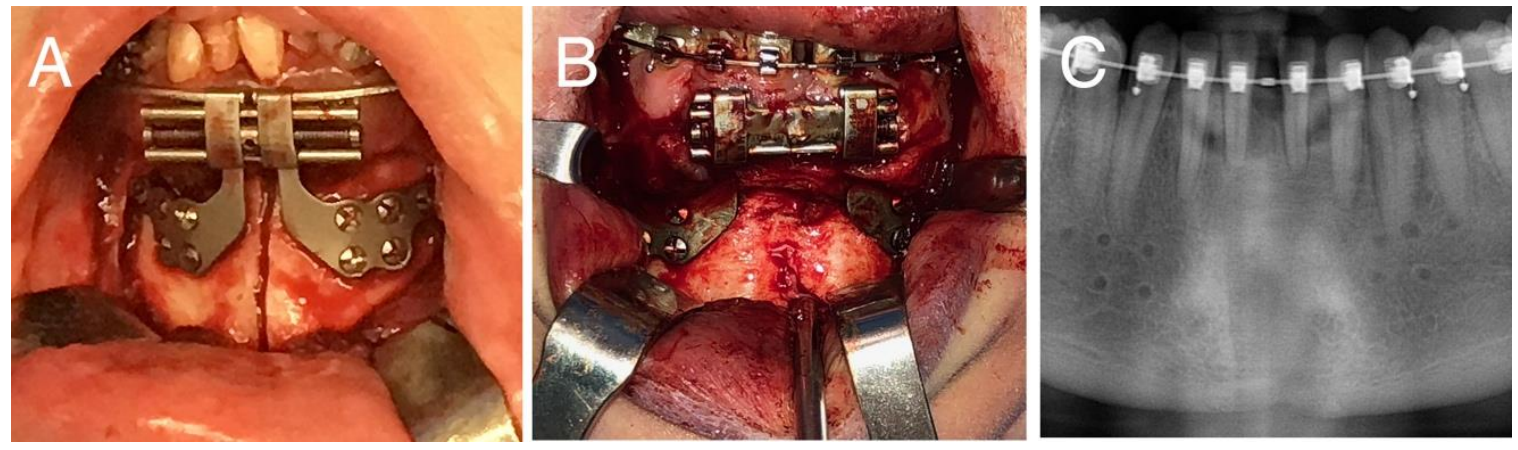
Figure 19. Progress photograhy at 69 weeks. Significant widening of the dental arches $(A, C)$. Class I occlusion with normal overjet and overbite is achieved (B).

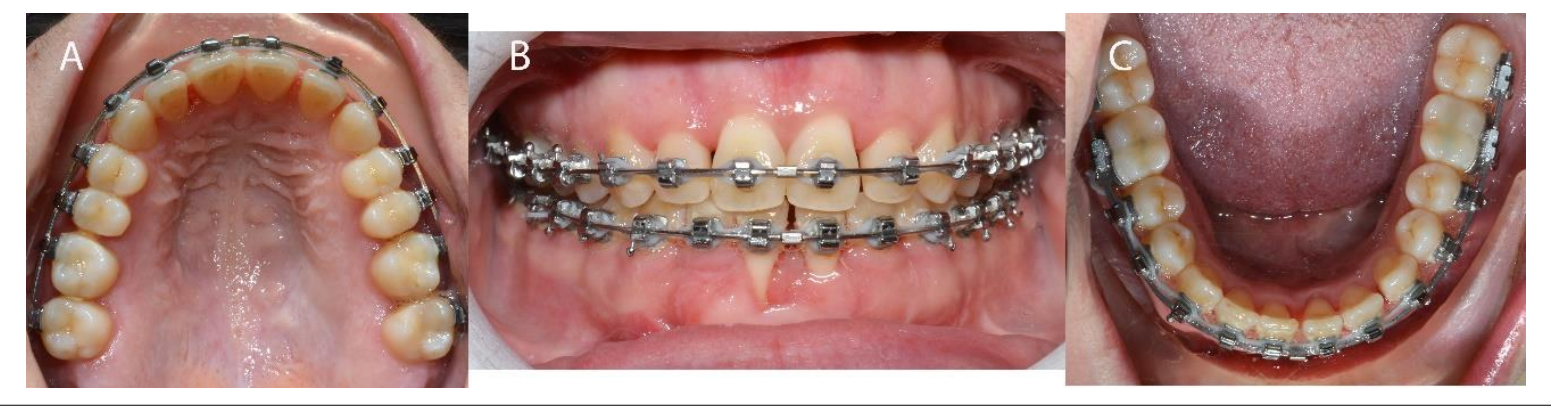

showed bimaxillary retrusion relative to cranial base (SNA $=75^{\circ} ; \mathrm{SNB}=72^{\circ}$ ). The smile review revealed a narrow maxilla with a wide buccal corridor and increased neck circumference (Figure 15).

The treatment plan included both maxillary and mandibular distractions. In the maxilla, we used a boneborne device (maxillary skeletal expander; Biomaterials Korea) that employs four bicortical miniscrews. The first device could not be activated further midway through the expansion. This is explained by bowing of the device and the fact that we did not reduce the rate of activation from 4/day to 2/day once a diastema was obtained. Nevertheless, we were able to achieve some midpalatal suture separation. This appliance was maintained for 4 months, then removed. One month later, a new appliance was put in place and we resumed the maxillary expansion.

The mandibular distraction occurred uneventfully, and $9.5 \mathrm{~mm}$ of distraction was achieved in 20 days (Bologna distractor). Figure 16 shows the outcome at the end of the second maxillary distraction phase and 5 months after the end of mandibular distraction.

Progress photo (Figure 16) and posteroanterior cephalogram (Figure 17B) at the end of the second maxillary distraction phase $(5$ months postmandibular distraction) show an increased first molar distance of 9.7 $\mathrm{mm}$ in the maxilla and $7 \mathrm{~mm}$ in the mandible (Table 1).

The canine width increased 7.7 in the maxilla and 6 $\mathrm{mm}$ in the mandible. The skeletal change of the maxilla at Jugula (Jg) was $4.8 \mathrm{~mm}$ and the nasal cavity width increased by $4.7 \mathrm{~mm}$.

The posteroanterior cephalogram shows mandibular distraction healing at 5 months and the end of the second maxillary expansion phase. Significant separation of the mid-palatal suture can be seen despite not using a surgical approach. Mandibular distraction at the osteotomy site was $10 \mathrm{~mm}$.

The patient reported a reduction in snoring, but she still required the use of continuous positive airway pressure to prevent daytime sleepiness. However, some of her daytime sleepiness could be explained by the antianxiety medication she was prescribed.

The mandibular device was removed at 37 weeks after surgery. Figure 18, A and B shows the amount of expansion achieved and the excellent bone formation at the symphysis except for a mesial bone defect at the lower left central incisor. This can be explained by root proximity to the surgical cut. Also, the body of the distraction device does not have a relief of 2 to $3 \mathrm{~mm}$ from the gingiva buccal to the incisors. This likely caused the incisors to come in contact as the crowding was managed. Despite reinforcing the importance of flossing, the patient's lack of oral hygiene probably contributed to this condition.

Polysomnography was performed 15 weeks after the removal of the mandibular distraction device. It revealed an AHI of 6 events/h, which is a significant improvement compared to the initial polysomnography. This improvement cannot be explained by loss of weight as the patient gains $13 \mathrm{~kg}$ between the first and second polysomnography.

Progress photography at 69 weeks intro treatment reveals class I relationship with ideal overate and overbite (Figure 19). A free gingival graft had to be done because the teeth had no relief with the distraction device and it damaged the mucogingival attachment. Significant widening of the maxillary and mandibular dental arches was obtained (Figure $19 \mathrm{~A}$ and C). The second surgical MMA phase was reassess and planned. The risk and benefit was discussed with the patient.

\section{DISCUSSION}

These two patients had a severe transverse deficiency of both arches. A normal transverse relationship was achieved by combined maxillary and mandibular distraction.

The change in the airway shadow of patient \#1 can be explained by a possible change of head posture, but more likely by a more forward rested position of the tongue obtained by the $8 \mathrm{~mm}$ of increased arched width, which allowed for an increased space between the dental arches. The reduction of the AHI of patient \#2 is significant and can be explained mainly by the orthognathic surgery (widening of both maxilla and mandible) and, to some extent, by the septoplasty and inferior turbinoplasty.

Miniscrew-assisted rapid palatal expansion (MARPE) is a new technique that permits nonsurgical maxillary 
skeletal expansion in adults although there is some age limitation. ${ }^{14-16}$ Data show an increased basal expansion of the maxilla using MARPE as compared to SARPE. This is explained by the significant lateral displacement of the zygomaticomaxillary complex provided by a boneanchored device. ${ }^{14}$ With the SARPE technique, the hemimaxilla rotates at the lateral osteotomy cut, ${ }^{9}$ whereas with MARPE the rotation of the hemimaxilla occurs at the frontozygomatic suture. ${ }^{14}$ MARPE produces skeletal change in the transverse dimension that results in an increased nasal cavity volume in the constricted airway, thereby facilitating nasal breathing. ${ }^{17} \mathrm{~A}$ recent study demonstrated that MARPE has a significant effect on improving respiratory muscle strength, and nasal and oral peak airflow. ${ }^{18}$ Patient \#2 had nearly a three fold enlargement of the nasal cavity width compared to patient $\# 1$.

Both the short- and long-term effects of expansion should be considered when planning maxillomandibular expansion. The expansion achieved from a segmented Le Fort 1 osteotomy does not permit an expansion of great magnitude. SARPE allows for a larger expansion, but dental relapse may occur despite the stability of the skeletal expansion. ${ }^{9}$

MARPE is a nonsurgical approach to maxillary expansion. It has been shown to provide significant change in the midface and the nasopharyngeal complex while providing increased expansion.

Periodontally accelerated osteogenic orthodontics therapy, also known as Wilckodontics, could be considered, but reports show that increased intermolar and intercanine expansion is limited to $2 \mathrm{~mm} .{ }^{19}$ Our patients obtained 8 and $7 \mathrm{~mm}$ of intermolar width and 12 and $6 \mathrm{~mm}$ intercanine width, respectively. Such expansion is beyond the scope of periodontally accelerated osteogenic orthodontics. Mandibular symphyseal distraction osteogenesis showed good long-term skeletal and dental stability. ${ }^{11,12}$

\section{CONCLUSION}

Transverse relationships may be forgotten dimensions when assessing the role of craniofacial deficiency in OSA, but recent reports confirm that normalizing the transverse dimension may help.

Increasing the transverse dimension provided functional benefit for these patients resulting in decreased snoring and a good occlusion. Transverse distraction osteogenesis of both maxilla and mandible followed by bimaxillary advancement, when indicated, might be more effective than MMA alone. Orthodontic-orthognathic treatment options should be evaluated in most patients experiencing OSA.

A surgical orthodontic approach offers a definitive solution to most patients having OSA.

\section{ACKNOWLEDGEMENT}

The author thanks Dr. Carl Bouchard and Dr Michel Giguère and Dre Melinda Paris, oral and maxillofacial surgeon at Hôpital l'Enfant-Jésus, for providing careful surgical treatment of patient 1 and 2 respectively and Dr. Louis Mercuri and Dr. Reginald Goodday for reviewing the manuscript.

Both patients completed a written informed consent for the use of their data for publication.

\section{REFERENCES}

1. Behrents RG, Shelgikar AV, Conley RS, et al. Obstructive sleep apnea and orthodontics: An American Association of Orthodontists White Paper. Am J Orthod Dentofacial Orthop. 2019;156(1):13-28 e1.

2. Beaupré A., et al., Apnée obstructive du sommeil et autres troubles respiratoires du sommeil. Guide d'exercice du Collège des médecins du Québec. 2014.

3. Goodday R. Diagnosis, treatment planning, and surgical correction of obstructive sleep apnea. J Oral Maxillofac Surg, 2009;67(10):21832196.

4. Goodday RH, Bourque SE, Edwards PB. Objective and subjective outcomes following maxillomandibular advancement surgery for treatment of patients with extremely severe obstructive sleep apnea (apnea-hypopnea index >100). J Oral Maxillofac Surg. 2016;74(3):583-589.

5. Mostafiz WR, Carley DW, Viana MGC, et al. Changes in sleep and airway variables in patients with obstructive sleep apnea after mandibular advancement splint treatment. Am J Orthod Dentofacial Orthop. 2019;155(4):498-508.

6. Wang X, Gong X, Yu Z, Gao X, Zhao Y. Follow-up study of dental and skeletal changes in patients with obstructive sleep apnea and hypopnea syndrome with long-term treatment with the Silensor appliance. Am J Orthod Dentofacial Orthop. 2015;147(5):559-565.

7. Goodday R, Bourque S. Subjective outcomes of maxillomandibular advancement surgery for treatment of obstructive sleep apnea syndrome. J Oral Maxillofac Surg. 2012;70(2):417-420.

8. Conley RS, Legan HL. Correction of severe obstructive sleep apnea with bimaxillary transverse distraction osteogenesis and maxillomandibular advancement. Am J Orthod Dentofacial Orthop. 2006;129(2):283-292.

9. Chamberland S, Proffit WR. Short-term and long-term stability of surgically assisted rapid palatal expansion revisited. Am J Orthod Dentofacial Orthop. 2011; 139(6): 815-822 e1.

10. Niculescu JA, King JW, Lindauer SJ. Skeletal and dental effects of tooth-borne versus hybrid devices for mandibular symphyseal distraction osteogenesis. Angle Orthod. 2014;84(1):68-75.

11. King JW, Wallace JC, Winter DL, Niculescu JA. Long-term skeletal and dental stability of mandibular symphyseal distraction osteogenesis with a hybrid distractor. Am J Orthod Dentofacial Orthop. 2012;41(1):60-70.

12. Durham JN, King JW, Robinson QC, Trojan TM. Long-term skeletodental stability of mandibular symphyseal distraction osteogenesis: Tooth-borne vs hybrid distraction appliances. Angle Orthod. 2017; 87(2):246-253.

13. Chamberland S, Proffit WR. Closer look at the stability of surgically assisted rapid palatal expansion. J Oral Maxillofac Surg. 2008; 66(9):1895-1900.

14. Cantarella D, Dominguez-Mompell R, Moschik C, et al. Midfacial changes in the coronal plane induced by microimplant-supported skeletal expander, studied with cone-beam computed tomography 
images. Am J Orthod Dentofacial Orthop. 2018;154(3):337-345.

15. Brunetto DP, Sant'Anna EF, Machado AW, Moon W. Non-surgical treatment of transverse deficiency in adults using Microimplantassisted Rapid Palatal Expansion (MARPE). Dental Press J Orthod. 2017; 22(1):110-125.

16. Cantarella D, Dominguez-Mompell R2, Mallya S, et al. Changes in the midpalatal and pterygopalatine sutures induced by micro-implantsupported skeletal expander, analyzed with a novel 3D method based on CBCT imaging. Prog Orthod. 2017;18(1):34.

17. Carlson, C, Sung J, McComb RW, Machado AW, Moon W. Microimplant-assisted rapid palatal expansion appliance to orthopedically correct transverse maxillary deficiency in an adult. Am J Orthod Dentofacial Orthop. 2016;149(5): 716-728.

18. Storto CJ, Garcez AS, Suzuki H, et al. Assessment of respiratory muscle strength and airflow before and after microimplant-assisted rapid palatal expansion. Angle Orthod. 2019; 89(5): 713-720.

19. Ferguson DJ, et al. Stability of the mandibular dental arch following periodontally accelerated osteogenic orthodontics therapy: Preliminary studies. Semin Orthod. 2014;20(3):239-246.

\section{SUBMISSION \& CORRESPONDENCE INFORMATION}

\section{Submitted for publication September 8, 2019}

Submitted in final revised form December 18, 2019

Accepted for publication January 2, 2020

Address correspondence to: Sylvain Chamberland D.M.D., M.Sc., F.R.C.D. (C), 10345 Boul. de l'Ormiere Quebec, Qc, Canada G2B 3L2; Email: drsylchamberland@videotron.ca

\section{DISCLOSURE STATEMENT}

The author reports no conflicts of interest. 